\title{
Cruzando olhares: estabelecendo diálogos entre E.P. Thompson e Angela Davis
}

\author{
Exchanging glances: establishing a conversation between \\ E.P. Thompson and Angela Davis
}

\section{Fernando Cauduro Pureza*}

Resumo: O presente artigo propõe um diálogo entre a obra do historiador marxista E.P. Thompson e da filósofa e militante negra americana, Angela Davis. Trata-se de um esforço preliminar que, não obstante as dificuldades em criar canais de diálogos entre obras tão distintas, propõe discutir categorias como experiência, relações sociais, exploração, opressão e alienação a partir de debates fundamentados em textos de autores ligados tanto a Davis quanto a Thompson. Dessa forma, espera-se com isso contribuir para um debate mais amplo sobre os ganhos que a História Social do Trabalho pode ter a partir de um olhar mais sensivel para as diferentes relações sociais de dominação e resistência no capitalismo.

Palavras-chave: E.P. Thompson; Angela Davis; experiência.

Abstract: The following paper intends to establish a dialogue between the works of the Marxist historian E.P. Thompson and the philosopher and black activist Angela Davis. It is a preliminary effort that, although it has some hardships in creating channels of communication between such different works, it can discusses some categories such as experience, social relations, exploitation, oppression and alienation, from debates based upon texts and works written by authors close to Davis and Thompson. In this way, we hope that this paper can contribute to a much broader debate around what the Social History of Labor may gain when we have a more sensitive way of looking to the different social relations of dominance and resistance in capitalism.

Keywords: E.P. Thompson; Angela Davis; experience.

* Doutor em História pela Universidade Federal do Rio Grande do Sul e Professor Adjunto da Universidade Federal da Paraíba. E-mail: fcpureza@gmail.com. ORCID: https://orcid.org/00000001-6363-0753. 


\section{Introdução: a proposta de cruzar olhares}

Somente no ano de 2016, a obra da filósofa e ativista americana Angela Davis passou a ser traduzida e publicada no Brasil, em importante esforço editorial da editora Boitempo. Até então, o acesso aos seus livros era limitado a quem dominava o idioma inglês ou conseguia acesso a traduções em outras línguas como o espanhol ou o francês. A obra escolhida para a sua primeira tradução foi Mulheres, raça e classe, publicada originalmente em 1983, mas, mesmo diante da diferença temporal, ela teve amplo impacto entre os leitores brasileiros. Trata-se, afinal, de um ensaio de caráter historiográfico (ainda que não seja feito por uma historiadora) e que procura relacionar a formação das lutas sociais na história dos Estados Unidos a partir de uma perspectiva "de baixo", estabelecendo múltiplos cruzamentos analíticos entre as categorias de raça, gênero e classe. ${ }^{1}$

Propor, portanto, um diálogo entre Angela Davis e Edward Thompson é algo que parte invariavelmente de um historiador que busca entender os possíveis pontos de aproximação nas obras de autores que dificilmente cruzaram seus olhares de fato. É difícil afirmar com precisão se ambos chegaram a ler um a obra do outro - e qualquer afirmação nesse sentido é arriscada, já que eles partiram de diferentes tradições dentro do marxismo para consolidar suas trajetórias políticas e teóricas. ${ }^{2}$ O campo da experiência vivida também os distingue: um acadêmico envolvido na luta antifascista dos anos 1940 e que reconstrói a nova esquerda britânica para além da ortodoxia stalinista de um lado; uma filósofa negra estadunidense, que atuou décadas no Partido Comunista e que se concentrou na luta das mulheres negras nos Estados Unidos e nas Américas como um todo. Um pacifista na luta contra a proliferação de armas nucleares e uma militante contra o encarceramento em massa de homens e mulheres negras. Em comum, perspectivas emancipatórias, mas cuja diversidade exige um esforço de análise para estabelecer aproximações que possam ajudar os historiadores sociais a lidar com autores tão diferentes.

Em linhas gerais, esse ensaio dedica-se não apenas a propor um cruzamento do qual seu autor acredita ser profícuo para os historiadores sociais - em especial,

\footnotetext{
Ainda que considere esse um trabalho de caráter historiográfico, a ênfase principal de Davis se concentra na história dos Estados Unidos e, portanto, dialoga principalmente com historiadores e historiadoras americanos e americanas. Nesse caso, não está no horizonte desse artigo uma discussão mais ampla sobre o que fundamenta o recorte historiográfico explorado pela autora e o diálogo que ela trava com esses historiadores.

2 A ideia de tradição dentro do marxismo aqui está diretamente baseada no debate entre Thompson e Leszek Kolakowski no qual o historiador britânico procurou definir o marxismo como uma tradição onde estão combinadas "uma pluralidade de vozes conflitantes", ecletismo e abrangência. Ver: THOMPSON, E.P. An open letter to Leszek Kolakowski. In: THOMPSON, E.P. The poverty of theory and other essays. Londres: Monthly Review Press, 2008. p. 326.
} 
para a História Social do Trabalho. Trata-se também de uma homenagem ao trabalho da professora Beatriz Loner, considerando seu pioneirismo nas reflexões sobre esses cruzamentos dentro de nosso campo de estudos.

\section{Experiências e produção de sentido}

É inevitável, ao falarmos de E.P. Thompson, reconhecer seu mérito ao trazer a questão da experiência para o centro do debate entre historiadores e historiadoras. ${ }^{3}$ Ainda que se considere as críticas que o termo recebeu vindas de historiadoras como Joan Scott ${ }^{4}$ problematizem o conceito e seus limites analíticos, não são poucos aqueles que, dentre nós, se valem de definições thompsonianas acerca do termo. Ele ganhou propriedades de conceito central, que estabelece ligações com diferentes esferas daquilo que é vivido pelos sujeitos e que eles são capazes de dar sentido. Essa junção permite que o vivido não seja apenas uma existência desprovida de sentido, mas um constante sentir que entrecruza determinações objetivas e subjetivas. Afinal, citando aqui o próprio Thompson, as pessoas "também experimentaram sua experiência como sentimento e lidam com esses sentimentos na cultura, como normas, obrigações familiares e de parentesco, e reciprocidades, como valores ou (através de formas mais elaboradas) na arte ou nas convicções religiosas". 5

Essa ideia de "junção", entre o que é objetivo e subjetivo, ou aquilo que pertence ao ser social e à consciência social nos obriga a pensar, invariavelmente, que a chave crucial da análise dos historiadores influenciados por essa visão é a de passar a olhar não para as determinações objetivas, mas pela forma como as determinações são experimentadas pelos sujeitos. Como Ellen Wood já propôs anteriormente, as formas pelas quais "as pressões determinantes dos processos estruturados são sentidas e manipuladas pelas pessoas" ${ }^{6}$ passam a se tornar fundamentais para a perspectiva de uma história vista de baixo.

3 O volume de obras que contemplam a questão da experiência em Thompson é demasiadamente volumoso para ser referenciado aqui. A título de lembrança, alguns textos podem ser citados para entender a sua influência no contexto brasileiro, mas certamente há muitos outros: MATTOS, Marcelo Badaró. E.P. Thompson no Brasil. Revista Outubro, n. 14, $2^{\circ}$ semestre de 2006. NEGRO, Antonio Luigi. E.P. Thompson no Brasil: recepção e usos. Crítica Marxista, n. 39, 2014. FORTES, Alexandre. Formação de classe e participação política: E.P. Thompson e o populismo. Anos 90, v. 17, n. 31, 2010. MACEDO, Francisco Barbosa de. $\mathbf{O}$ (re)fazer-se da historiografia: a obra de E.P. Thompson na produção discente do Programa de Pós-Graduação em História da Unicamp (19822002). 2017. Tese (Doutorado em História) - Universidade de São Paulo, São Paulo, 2017.

4 SCOTT, Joan. A invisibilidade da experiência. Proj. História, São Paulo, v. 16, p. 297-325, fev. 1998.

5 THOMPSON, E.P. A miséria da teoria, ou um planetário de erros. Uma crítica ao pensamento de Althusser. Rio de Janeiro: Zahar Editores, 1981. p. 189.

6 WOOD, Ellen. Democracia contra capitalismo: a renovação do materialismo histórico. São Paulo: Boitempo, 2003. p. 90. 
Talvez aqui seja fortuito retornar ao texto de Davis. Se entendermos Mulheres, raça e classe como um projeto historiográfico, ainda assim nos deparamos com a ausência de preocupação acerca de um conceito funcional para historiadores e historiadoras refletirem sobre os cruzamentos entre as diferentes categorias sociais. A própria noção de interseccionalidade, que nos dias de hoje tem a obra de Angela Davis como texto fundacional, foi concebida inicialmente a partir do trabalho da jurista americana Kimberlé Crenshaw, "Demarginalizing the intersection of race and sex". ${ }^{7}$ Todavia, a ideia de articular diferentes categorias na luta por emancipação social em um ensaio de ênfase histórica exigia uma articulação difícil de ser feita, no qual a filósofa americana encontrou um ponto de conexão:

Se, e quando, alguém conseguir acabar, do ponto de vista histórico, com os malentendidos sobre as experiências das mulheres negras escravizadas, ela (ou ele) terá prestado um serviço inestimável. Não é apenas pela precisão histórica que um estudo desses deve ser realizado; as lições que ele pode reunir sobre a era escravista trarão esclarecimentos sobre a luta atual das mulheres negras e de todas as mulheres em busca de emancipação. Como leiga, posso apenas propor algumas hipóteses que talvez sejam capazes de orientar um reexame da história das mulheres negras durante a escravidão. ${ }^{8}$

Esse uso do termo "experiência" aqui não parece ter maiores preocupações teóricas, é bem verdade. Pode se dizer que o uso do termo remete invariavelmente à vivência do sujeito, uma vivência resumida em certo sentido à materialidade daquilo que é vivido. Mas se considerarmos a ênfase que Thompson confere à ideia de "experiência como sentimento", começamos a ver outras aproximações, afinal, como Davis bem coloca, as experiências das mulheres negras na escravidão nos permitem perceber o seu protagonismo nas lutas pela igualdade de gênero, pela emancipação, pelos direitos civis e pela igualdade da classe trabalhadora nos Estados Unidos dos séculos XIX e XX.

Ao afirmar que a opressão da escravidão negra tinha um corte específico sexual, Davis ressalta que a violência sexual "era uma expressão ostensiva do domínio econômico do proprietário e do controle do feitor sobre as mulheres negras na condição de trabalhadoras". ${ }^{9}$ Essa leitura compreende que um outro tipo de experiência condicionava a exploração econômica, diferindo as mulheres escravizadas dos homens. E, se por um lado a violência sexual criava condições

CRENSHAW, Kimberlé. Demarginalizing the Intersection of Race and Sex: a Black Feminist critique of antidiscrimination doctrine, feminist theory and antiracist politics. University of Chicago Legal Forum, Issue 1, article 8, vol. 1989.

8 DAVIS, Angela. Mulheres, raça e classe. São Paulo: Boitempo, 2016. p. 24.

9 Ibidem, p. 20. 
para um tipo de experiência singular da escravidão, por outro, segundo a autora, a vida doméstica propiciava, a homens e mulheres, "o único espaço em que podiam vivenciar verdadeiramente suas experiências como seres humanos". 10 Embora o sentido do termo "experiência" ressoe de forma diferente, há algo mais amplo, que não envolve somente a experiência do trabalho, mas outras experiências constitutivas da sua condição, opressões outras que constroem sentidos plurais que afetam o mundo do trabalho, mas vão além dele.

A potência historiográfica do conceito de experiência nos trabalhos sobre a escravidão e o pós-abolição no Brasil não é propriamente uma novidade se considerarmos textos basilares da historiografia brasileira. ${ }^{11}$ Mas, chama atenção o emprego do termo que Davis sugere, pois sua amplitude retoma a ideia de que o conceito não pode se resumir à exploração do trabalho escravo unicamente. De fato, a experiência envolveria uma categoria que ao mesmo tempo em que estivesse relacionado à opressão a qual a mulher escravizada estava sujeita, ela também apostaria em questões como, por exemplo, a fruição de uma vida doméstica na qual poderia ser possível construir sentidos e sentimentos contrários à exploração do trabalho escravo. Em outras palavras, o sentido da experiência que Davis resgata é a de sujeitos capazes de produzir os próprios sentidos de sua vida (seja por meio do trabalho, dos ritos, das festas, dos afetos), não obstante toda a violência que recai sobre elas.

Há, em especial, um ponto no qual esse salto qualitativo talvez fique evidente na obra de Angela Davis. Considerando o uso de obras historiográficas que a autora faz para discutir o trabalho das mulheres escravizadas no século XIX, destacam-se obras de historiadores americanos como Eugene Genovese e Herbert Gutman, que acabaram aproximando-se diretamente do trabalho de E.P. Thompson. É possível que o conceito tenha sido transferido de forma um tanto quanto "emprestada", sem maiores reflexões, mas é justamente a partir da crítica que Davis elabora a esses

10 Ibidem, p. 33. Todavia, à luz de uma historiografia cada vez mais voltada para a vida de homens e mulheres escravizados, possivelmente a noção de "vida doméstica" precise de maior problematização. A rigor, obras já consideradas canônicas na historiografia brasileira da escravidão tais como "A morte é uma festa", de João José Reis, ou "Na senzala, uma flor", de Robert Slenes, para citar algumas, são referências que permitem aprofundar esse questionamento. Não obstante, a autora considera importante abrir uma espécie de corte no âmbito da experiência de escravizados que era, em certa medida, capaz de diferenciar a violência da escravidão de outras experiências baseadas nos rituais, nas festas, nos afetos etc.

11 O principal texto para efetivamente mapear a influência thompsoniana nos novos estudos sobre a escravidão na historiografia brasileira é o artigo de Sidney Chalhoub e Fernando Teixeira da Silva (Sujeitos no imaginário acadêmico: escravos e trabalhadores na historiografia brasileira desde os anos 1980. Cadernos AEL, v. 14, n. 16, p. 13-47, 2009). Todavia, balanços mais recentes têm demonstrado que a História Social do Trabalho ainda possui um diálogo limitado com as questões referentes ao pós-abolição, à raça e à cor dos trabalhadores. Para mais, ver o importante artigo de Álvaro Nascimento (Trabalhadores negros e "paradigma da ausência": contribuições à História Social do Trabalho no Brasil. Estudos Históricos, v. 29, n. 59, p. 607-626, 2016). 
autores que é possível verificar outros indícios que mostram uma leitura mais autoral e criativa da filósofa americana para com o termo.

Ao tratar da continuidade do estupro de homens brancos sobre mulheres negras, Davis enfatiza a ideia de uma "experiência histórica" combinada a uma "ideologia racista", ${ }^{12}$ na qual o corpo de mulher negra aparece como "convite aberto ao estupro". Ao discutir a experiência das mulheres negras que trabalhavam fora de casa ao longo da escravidão - e posteriormente - há também a ênfase numa "experiência histórica". ${ }^{13} \mathrm{~A}$ ideia de que as experiências se perpetuam historicamente ao mesmo tempo em que são submetidas a transformações mediante as lutas permite uma espécie de refinamento, que pode ser visto na seguinte passagem:

As Elizas, se existiram, certamente foram as exceções em meio à maioria das mulheres negras. Elas não representam, em hipótese alguma, experiências acumuladas por todas essas mulheres que labutaram sob o chicote de seus senhores, trabalharam para sua família, protegendo-a, lutaram contra a escravidão e foram espancadas, estupradas, mas nunca subjugadas. Foram essas mulheres que transmitiram para suas descendentes do sexo feminino, nominalmente livres, um legado de trabalho duro, perseverança e autossuficiência, um legado de tenacidade, resistência e insistência na igualdade sexual - em resumo, um legado que explicita os parâmetros para uma nova condição da mulher. ${ }^{14}$

Há aqui uma semelhança impressionante com uma famosa passagem de E.P. Thompson na introdução da obra A formação da classe operária inglesa.

Estou tentando resgatar o pobre tecelão de malhas, o meeiro luddita, o tecelão do "obsoleto" tear manual, o artesão "utópico" e mesmo o iludido seguidor de Joanna Southcott, dos imensos ares superiores de condescendência da posteridade. Seus ofícios e tradições podiam estar desaparecendo. Sua hostilidade frente ao novo industrialismo podia ser retrógrada. Seus ideais comunitários podiam ser fantasiosos. Suas conspirações insurrecionais podiam ser temerárias. Mas eles viveram nesses tempos de aguda perturbação social, e nós não. Suas aspirações eram válidas nos termos de sua própria experiência; se foram vítimas acidentais da história, continuam a ser, condenados em vida, vítimas acidentais. ${ }^{15}$

Asobreposição das duas citações não permite, claro, comparações instantâneas - embora haja algo na forma estilística que indique uma aproximação, sem dúvida. Mas há ganchos que conectam os termos empregados. Em ambos, o foco na experiência pressupõe uma multiplicidade - no caso de Thompson, com ênfase naquilo que é constitutivo da classe trabalhadora inglesa e enquanto em Davis o foco

12 DAVIS, op. cit., p. 191.

13 Ibidem, p. 220.

14 Ibidem, p. 41.

15 THOMPSON, E.P. A formação da classe operária inglesa. Vol. 1.: A Árvore da Liberdade. Rio de Janeiro: Paz e Terra, 2004. p. 13. 
é no que é constitutivo da luta em prol de uma nova condição da mulher. Mas, mais do que isso, os termos "transmissão" e "resgate" indicam uma relação direta com a noção de experiência, estabelecendo dois significados: a experiência transmitida pelos sujeitos por um lado e a experiência resgatada pelos historiadores por outro. Uma não exclui a outra, é bem verdade - e ambos autores parecem reconhecer isso. Mas o que está presente em ambas é a ideia de experiências que não estão visíveis na superfície, que exigem um trabalho analítico mais criterioso para serem recuperadas. Elas se escondem como táticas de sobrevivência, subterfúgios que se convertiam em armas para resistir a uma dominação que era imposta a esses sujeitos - sejam elas as mulheres escravizadas nos Estados Unidos no século XIX, sejam eles os operários ingleses no início do processo de industrialização.

Contudo, há que se considerar que são também experiências distintas. $O$ que é constitutivo da experiência das mulheres escravizadas e dos trabalhadores ingleses não são as mesmas pressões estruturantes. As formas pelas quais o capitalismo se desenvolvera ao longo do tempo e em espaços distintos gerou formas de exploração completamente diferentes e, como Walter Johnson propôs em seu artigo "The pedestal and the veil", a própria análise de Marx sobre o desenvolvimento capitalista poderia ter sido muito distinta caso o filósofo alemão tivesse substituído a metáfora do casaco de linho por uma peça feita de algodão. ${ }^{16}$ Nesse ponto, o foco de Davis não atende uma "particularidade" da classe trabalhadora, mas pretende ver justamente como é possível conceber os cruzamentos entre lutas de classes, gênero e raça dentro do capitalismo - algo que certamente se propõe a ir além das pretensões de E.P. Thompson.

\section{Gênero, raça e classe - a ideia de relação}

Em seu ensaio seminal, "Classe como processo e como relação", a historiadora Ellen Meiksins Wood afirmava que uma das principais contribuições thompsonianas havia sido um trabalho teórico capaz de apreender os processos de formação de classe por dois métodos simultâneos: o primeiro, enfocando justamente no caráter processual dessa formação (um processo que não é linear e tampouco estável), enquanto o segundo focaria justamente na perspectiva de que a classe é sempre uma posição social relacional. Trata-se, contudo, de uma relação dual, "a que existe entre as classes e a que existe entre os membros da mesma classe". ${ }^{17}$

\footnotetext{
16 JOHNSON, Walter. The pedestal and the veil: rethinking the capitalism/slavery question. Journal of the Early Republic, v. 24, n. 2, p. 302, summer 2004.

17 WOOD, op. cit., p. 87.
} 
Olhando mais especificamente para o Brasil, uma leitura semelhante pode ser encontrada a partir da historiadora homenageada nesse dossiê, a professora Beatriz Loner, na sua obra Construção de classe: operários de Pelotas e Rio Grande. Ao explicar os primórdios de sua pesquisa referente à formação de classe dos operários de Pelotas e Rio Grande, no Rio Grande do Sul no final do século XIX e início do século $\mathrm{XX}$, Loner delimitou um dos aspectos de análise naquilo que chamou de "composição da classe operária e sua inter-relação com o contexto local". Isso implicaria reconhecer "fatores nacionais ou étnicos, o gênero, a história anterior desses diversos segmentos que compõem o operariado e a visão e a posição da sociedade local e do governo frente a eles", ${ }^{18}$ tudo isso como algo formativo de uma história operária comum.

Loner e Wood atentam, cada uma por uma perspectiva distinta, para um mesmo problema: como analisar as relações internas a uma classe social? Loner propôs um importante roteiro de pesquisa que impacta ainda hoje pesquisadores voltados tanto para temas referentes à classe, quanto à raça como quanto ao gênero.

Essa passagem, todavia, abre um outro leque de reflexões se a colocamos lado a lado de uma outra perspectiva, construída por Angela Davis, em uma conferência que a autora fez em São Luís, em 1997. O texto, intitulado "As mulheres negras na construção de uma nova utopia", foi referenciado no prefácio de Mulheres, raça e classe escrito pela filósofa Djamila Ribeiro. Nele, Davis destaca que:

As organizações de esquerda têm argumentado dentro de uma visão marxista e ortodoxa que a classe é a coisa mais importante. Claro que classe é importante. É preciso compreender que classe informa a raça. Mas raça, também, informa a classe. E gênero informa a classe. Raça é a maneira como a classe é vivida. Da mesma forma que gênero é a maneira como a raça é vivida. A gente precisa refletir bastante para perceber as interseções entre raça, classe e gênero, de forma a perceber que entre essas categorias existem relações que são mútuas e outras que são cruzadas. Ninguém pode assumir a primazia de uma categoria sobre as outras. ${ }^{19}$

Essa citação abre uma série de prerrogativas para pensarmos, de forma prática, como múltiplas categorias de análise podem ser trabalhadas por historiadores sociais. Mas se seguirmos as perspectivas de Wood na sua análise quanto à classe, podemos pressupor que não apenas a classe, mas também raça e gênero caem na mesma prerrogativa de serem entendidas tanto como processo quanto relação. E,

18 LONER, Beatriz. Construção de classe: operários de Pelotas e Rio Grande. 2. ed. Pelotas: Ed. UFPEL, 2016. p. 16.

19 Grifos meus. DAVIS, Angela. As mulheres negras na construção de uma nova utopia. Gelédes, 12 jul. 2011. Disponível em: https://www.geledes.org.br/as-mulheres-negras-na-construcao-de-umanova-utopia-angela-davis/. Acesso em: 22 ago. 2019. 
se entendidas enquanto relação, abrimos uma outra possibilidade de análise, mais próxima do que Davis discute em suas obras, que é justamente como as diferenças constituem sentimentos que unificam classe, raça e gênero. Em outras palavras, o conectivo de "informar" talvez ganhe mais substância se retomarmos a noção de experiência articulada tanto por Thompson quanto por Davis.

Não faltam trabalhos recentes na História do Trabalho que exemplifiquem essas questões. No $30^{\circ}$ Simpósio Nacional da ANPUH, ocorrido em Recife desse ano (2019), o GT Mundos do Trabalho organizou três simpósios diferentes, o que serve minimamente como ilustração da pluralidade e da riqueza de análises capazes de discutir as fronteiras entre trabalho livre e trabalho escravo; as estratégias de racialização de trabalhadores no Brasil; suas organizações sociais, políticas e culturais; o trabalho feminino e as relações de gênero; questões referentes à sexualidade de trabalhadores e trabalhadoras; a etnicidade como componente da formação da classe; a cultura dos trabalhadores etc. É bem certo que a classe ainda ganha proeminência como análise em muitos casos, mas seus espaços de conexão se ampliam quando os historiadores passam a investigar como as diferentes experiências se cruzam. Dessa forma, também os espaços onde elas se articulam ou não se articulam - se tornam valiosos a serem estudados.

Todavia, o enfoque de Davis parece apontar justamente para algo maior: ou seja, como as pessoas vivem as categorias de raça, gênero e classe que são construídas socialmente. Aqui, claro, viver não se trata só de uma relação passiva de experiência, se trata de construir (individualmente, mas também coletivamente) uma categoria que "informa" outras categorias. Raça e gênero não podem, por sua vez, serem entendidos somente como o espaço da opressão, mas também como espaços de resistência, que constroem formas específicas de resistir frente a uma forma de dominação. Retomando mais uma vez a obra de Beatriz Loner, creio que ali fica evidente um dos primeiros esforços historiográficos no Brasil em que essa noção de "categorias que informam categorias" pode ser apresentada. Ao discutir as associações dos espaços de Pelotas e Rio Grande, Loner separou as associações beneficentes, as associações operárias e as associações negras e concluiu que havia espaços de diálogos constantes entre elas. Os diálogos nem sempre eram fraternos, havia rivalidades entre elas - cujos conteúdos de classe ou raça afirmados em cada instituição podiam ser catalizadores dessas tensões. Embora o foco de Loner fosse, invariavelmente, a formação da classe operária, seu estudo sobre as associações negras chegou à conclusão de que os motivos que levavam os trabalhadores negros a se aproximarem das associações operárias eram substancialmente diferentes dos 
trabalhadores brancos. ${ }^{20}$ Nesse caso, sem entendermos como a raça informa a classe dificilmente poderíamos compreender como, em sentido dialético, a classe também informava a raça. $E$, somando a perspectiva de Davis, inserindo gênero aqui, vemos essa dialética se ampliar num esquema tridimensional, onde cada esfera de análise interage uma com a outra.

Para Davis, a questão central está justamente nas relações que informam outras relações, o que obriga historiadores e demais pensadores sociais a questionarem a estabilidade de conceitos como classe, gênero ou raça. $E$, numa perspectiva thompsoniana, se considerarmos as transformações históricas das experiências dos sujeitos nessa perspectiva "tridimensional", a noção de relação reivindicada por Wood ganha uma nova camada de complexidade, na qual demais categorias sociais ganham existência por meio da dualidade de uma relação interna e uma relação externa, Dito de outra forma, não apenas a classe, mas gênero e também raça possuem essa mesma dualidade. Assim, cada uma dessas categorias poderia ser entendida tanto na sua dimensão antagônica (ou seja, as tensões que existem entre diferentes classes, diferentes gêneros e diferentes raças) e na sua heterogeneidade interna (ou seja, as tensões que existem no interior de cada grupo social). E, dessa forma, a heterogeneidade das categorias abriria uma nova dinâmica de relações construídas tanto pela solidariedade como, por vezes, por rivalidades e antagonismos - e, convém dizer, nem a solidariedade e nem as rivalidades seriam posições estabelecidas a priori, dependendo sempre de um determinado contexto histórico capaz de elucidar as diferentes relações estabelecidas em determinada época.

Ao falar do papel da feminista americana histórica Susan B. Anthony nas tensões contra os sindicatos, Davis retoma o episódio de 1869 em que Anthony foi banida da convenção da Federação Sindical Nacional por "haver encorajado as tipógrafas a furar greve". Segundo a autora, havia entre as sufragistas americanas não apenas uma posição de primazia da categoria "mulher" sobre as demais, mas também posições antitrabalhadores e antinegras. ${ }^{21} \mathrm{E}$, não obstante, ao longo do século XIX e o início do século XX, como ressalta Davis, mulheres e homens negros se engajaram em lutas dos trabalhadores e trabalhadoras e defenderam o sufrágio feminino. Da mesma forma, como destaca Doug McAdam, jovens brancos, na década de 1960, migraram para os estados do sul dos Estados Unidos para fazer trabalho voluntário em prol da luta pelos direitos civis e pela conquista do sufrágio de homens e mulheres negras no chamado Freedom Summer. Ao longo da história da luta

\footnotetext{
LONER, op. cit. Ver em especial o capítulo 5, "Associações negras".

DAVIS, op. cit., 2016, p. 145.
} 
por direitos nos Estados Unidos, a construção da solidariedade como valor político serviu como contrapeso às tensões internas que existiam em termos de raça, classe e gênero. E como o próprio McAdam destaca, essa solidariedade acaba marcando uma profunda radicalização dos sujeitos em seus projetos políticos e pessoais. ${ }^{22} \mathrm{De}$ fato, conforme os laços de solidariedade se ampliam nessas múltiplas relações, os limites entre o pessoal e político se diluem - o que justifica o método biográfico que McAdam confere em seu estudo sobre os voluntários brancos no Freedom Summer.

A diluição dos limites entre pessoal e político acabam, por sua vez, mostrando como as relações travadas interna e externamente a um determinado grupo social são bastante fluídos. Como Davis destacara em sua palestra em 1997, "o grande desafio contemporâneo nos EUA é fazer a ligação entre o público e o privado, entre o pessoal e o político, de maneira a estabelecer a relação entre a violência doméstica e a pública". ${ }^{23} \mathrm{E}$ dessa ligação, um novo campo para pensarmos as formas pelas quais homens e mulheres, brancos e negras, trabalhadores ou capitalistas, experienciam determinadas relações sociais.

Nesse ponto, creio que o próprio E.P. Thompson estabeleceu as bases para esse diálogo em um ensaio de 1977 chamado "Folclore, Antropologia e História Social". Nele, o historiador inglês apresentou a antropólogos indianos algumas das suas ponderações sobre as relações entre as duas disciplinas e como o folclore, invariavelmente, seria o elemento crucial de algumas dessas articulações entre os campos. Preocupado com uma história vista de baixo, Thompson acaba por formular uma máxima importantíssima para os termos desse artigo:

\begin{abstract}
Não podemos entender o sistema agrário dos pequenos produtores sem investigar práticas hereditárias, os dotes e, quando for o caso, o ciclo do desenvolvimento familiar. Por sua vez, essas práticas se apoiam nas obrigações e reciprocidades do parentesco, cuja manutenção e observância serão frequentemente encontradas nos encargos particulares das mulheres. A "economia" só pode ser entendida no contexto de uma sociedade urdida assim. A vida "pública" emerge de dentro das densas determinações da vida "doméstica". ${ }^{24}$
\end{abstract}

Essa percepção thompsoniana retoma que os limites daquilo que parece sempre estrutural (a dizer, a economia, claro, mas também a política, ou a cultura) são construções de sujeitos que, diante de suas necessidades mais cotidianas, acabam por moldar essas estruturas. Dito de outra forma, aquilo que parece ao historiador de caráter pessoal e privado, o que parece ocorrer no âmbito doméstico, é capaz

22 MCADAM, Doug. Freedom Summer. Nova York: Oxford University Press, 1990. p. 234-235.

23 DAVIS, op. cit., 2011.

24 THOMPSON, E.P. Folclore, Antropologia e História Social. In: THOMPSON, E.P. As peculiaridades dos ingleses e outros artigos. Campinas: Ed. Unicamp, 2002. p. 234-235. Grifos meus. 
de determinar o espaço público. Isso não significa negar que as determinações da chamada vida pública não interfiram no espaço doméstico, mas nos dá a possibilidade de encarar de forma dialética essas relações, com muito mais fluidez do que certos esquemas. E, associada à leitura de Davis, trata-se de perceber que em ambos espaços, públicos ou privados, a vida social se constitui de forma inexoravelmente política.

De fato, numa leitura "davisiana" de Thompson, seria possível amparar essa ideia a partir da multiplicidade de lugares sociais onde as relações se estabelecem - a casa, o bar, a fábrica, o roçado, as praias, o comércio etc. Nesses espaços, raça, gênero e classe se constituem como formas de dividir o acesso a determinados recursos, a manutenção de determinados privilégios, ao controle sobre o trabalho, o lazer e o corpo. Na medida que se compreende que o foco são as relações estabelecidas entre os sujeitos, em toda sua complexidade, entende-se que os espaços são cruciais para essa análise. É neles que as noções de pertencimento a um determinado grupo são definidas - ainda que, como salienta Patricia Hill Collins, o lugar social das mulheres negras da classe trabalhadora está marcado pela posição de outsider within, forma específica de marginalidade que as deixa em posições sociais mais desprovidas de solidariedade perante os demais grupos. $^{25}$

Considerando essas questões, o espaço social onde as relações se desdobram, mais do que público e privado, acaba sendo eivado de interferências de diferentes esferas que condicionam identidades e comportamentos específicos. Para entender essas articulações, todavia, é preciso estabelecer o que fundamenta as diferentes experiências que constituem categorias como classe, gênero e raça, ou seja, o que conecta os indivíduos e lhes fornece uma gramática específica para significar aquilo que é vivido. E embora seja possível afirmar que uma linguagem não emerge do nada, os elementos mais determinantes para a formulação de um sentido às articulações e às solidariedades políticas em sua forma mais emancipatória acabam sendo fundamentais para uma análise social preocupada com a forma como os sujeitos experimentam as muitas relações de dominação a que eles e os outros estão submetidos.

25 COLLINS, Patricia Hill. Pensamento feminista negro. São Paulo: Boitempo, 2019. p. 45. É possível afirmar que o argumento de Collins situa a problematização interseccional a partir de uma lógica diferente da de McAdam. Para a autora, essa posição de marginalização específica que atinge as mulheres negras da classe trabalhadora as torna menos suscetíveis à solidariedade de trabalhadores e trabalhadoras brancas. Embora não seja possível discutir essa questão especificamente aqui, parece-me um interessante roteiro de pesquisa para pensar nas articulações de diferentes lutas políticas em termos de gênero, raça e classe. 


\title{
Exploração, opressão e alienação: vocábulos em intersecção
}

Em seu clássico livro $A$ formação da classe trabalhadora inglesa, Edward Thompson dedicou um capítulo inteiro de seu segundo volume para discutir a "exploração" enquanto um dos fundamentos cruciais para entender a experiência da classe trabalhadora. Ao invés de uma leitura mais ortodoxa, que procura quantificar e mensurar a exploração, Thompson propôs uma leitura qualitativa capaz de questionar a obsessão estatística de autores como Taylor ou Hayek, que passaram a identificar em indicadores positivos os avanços sociais oriundos da Revolução Industrial - questionando, assim, as chamadas leituras catastrofistas que concebiam a industrialização britânica como tragédia.

Thompson mostra que o debate sobre cifras possui valor, mas que ele ignorava de forma explícita algo maior, uma mudança de fundo na própria forma de exploração. Como o historiador inglês destaca:

\begin{abstract}
A relação de exploração é mais que a soma de injustiças e antagonismos mútuos. É uma relação que pode ser encontrada em diferentes contextos históricos sob formas distintas, que estão relacionadas a formas correspondentes de propriedade e poder estatal. A relação clássica de exploração da Revolução Industrial é despersonalizada, no sentido de que não admite qualquer das antigas obrigações de mutualidade - de paternalismo ou deferência, ou de interesses da 'Profissão'. [...] $O$ antagonismo é aceito como intrínseco às relações de produção. Funções de gerência ou supervisão demandam a repressão de todos os atributos, à exceção daqueles que promovam a expropriação do máximo de mais-valia do trabalho. Esta é a economia política que Marx dissecou n'O Capital. O trabalhador tornou-se um "instrumento" ou uma cifra, entre outras, no custo. ${ }^{26}$
\end{abstract}

O argumento de Thompson é extremamente importante para identificarmos na relação de exploração um fator constitutivo da formação da classe. Na medida em que são transformados em cifra, homens e mulheres passam a identificar uma nova forma de exploração e buscam, por sua vez, um novo vocabulário para dar sentido ao que estão vivenciando, essa nova forma de relacionar-se com o trabalho.

Essa experiência de sentir-se transformado em cifra, se visto a partir da lógica da escravidão, pode ser comparado com o processo pelo qual milhões de homens e mulheres foram transformados em cativos. O seu trabalho, nas Américas, passou a ser sujeito a mero cálculo econômico já a partir dos primeiros navios que abordaram no continente africano. E, não obstante, as experiências entre escravos de Benguela no século XVII e operários de Lancashire do século XIX

26 THOMPSON, E.P. A formação da classe operária inglesa. Vol. 2.: A Maldição de Adão. Rio de Janeiro: Paz e Terra, 1987. p. 28. 
foram significativamente diferentes, o que construiu uma outra noção de exploração diferente daquela a que Thompson se referia no trabalho assalariado dos ingleses entre 1790-1830. Segundo Robinson, W.E.B. DuBois, todavia, sintetizou a questão de forma bastante direta: não é necessariamente a escravidão, mas sim o trabalho de homens e mulheres negras que merece ser analisado como base crucial do desenvolvimento. ${ }^{27}$ Essa centralidade do trabalho desloca a questão sobre "trabalho livre" e "trabalho escravo" para pensarmos nas multiplicidades da forma do trabalho - em especial, na transição das abolições da escravidão e no período pós-emancipação nas Américas.

Algo semelhante pode ser visto no argumento de Angela Davis, em Mulheres, raça e classe. Ao discutir o papel das mulheres escravizadas na economia capitalista em seus primórdios, Davis destaca que "o ponto de partida de qualquer exploração da vida das mulheres negras na escravidão seria uma avaliação de seu papel como trabalhadoras", tendo em vista que as mulheres eram vistas como "unidades de trabalho lucrativas". ${ }^{28}$ Todavia, isso não pressupõe que, sob a égide do capital, homens, mulheres, brancos e negros, livres ou cativos, são todos equalizados numa mesma cifra. Há uma diferença evidente no valor do trabalho de todos que se dá, na falta de um mecanismo específico para o cálculo, na capacidade dos donos dos meios de produção, por um elemento singular: a capacidade de extração de mais-valia.

Essa capacidade, na leitura thompsoniana, pode ser traduzida por técnicas de administração e gerenciamento que criam mecanismos de repressão destinados a expropriação de mais-valia do trabalhador. Mas Davis propõe uma leitura singular sobre o processo referente às mulheres escravas. Segundo ela, as mulheres escravizadas "sofriam de forma diferente", pois eram "vítimas de abuso sexual e outros maus-tratos bárbaros que só poderiam ser infligidos a elas". Dessa forma:

A postura dos senhores em relação às escravas era regida pela conveniência: quando era lucrativo explorá-las como se fossem homens, eram vistas como desprovidas de gênero; mas, quando podiam ser exploradas, punidas e reprimidas de modos cabíveis apenas às mulheres, elas eram reduzidas exclusivamente a sua condição de fêmeas. ${ }^{29}$

27 Robinson cita a obra Black Reconstruction de W.E.B. Du Bois, destacando que a categoria "labor" (trabalho) precisa ser estudada para entender o papel dos trabalhadores e trabalhadoras negras no desenvolvimento americano. Nos termos de Du Bois, "it was thus the black worker, as founding stone of a new economic system in the nineteenth century and for the modern world, who brought civil war in America". Cf. DU BOIS, W.E.B. Black reconstruction in America: toward a history of the part of which Black folk played in the attempt to reconstruct democracy in America, 1860-1880. New Brunswick: Transaction Publishers, 2013. p. 47. Apud ROBINSON, Cedric. Black Marxism: the making of Black Radical tradition. Londres: University of North Carolina Press, 2000. p. 199.

28 DAVIS, op. cit., 2016, p. 17.

29 Ibidem, p. 19. 
O uso de termos como "exploradas, punidas e reprimidas" identifica aqui um processo correspondente ao que Thompson identifica no contexto britânico da Revolução Industrial - uma exploração, punição e repressão de trabalhadores, ou no caso, de trabalhadoras. Ao estarem mais suscetíveis a uma forma feminina de exploração, punição e repressão, isso as tornava mais vantajosas aos olhos de capitalistas que, por "conveniência", poderiam garantir maior extração de mais-valia.

A base desse tipo de opressão, no argumento de Davis, retoma a situação da dificuldade histórica de mulheres brancas em reconhecer as lutas de trabalhadoras domésticas, identificadas racialmente como mulheres negras. Utilizando da metáfora hegeliana do "senhor e do escravo", a filósofa americana destaca um tipo de relação na qual mesmo sujeitos historicamente oprimidos - trabalhadores e trabalhadoras - podiam reconhecer uma hierarquia em termos de acesso a direitos no mundo do trabalho. Ao referir-se ao artigo "A Nine-Hour Day for Domestic Servants", escrito em 1902, Angela Davis destaca essa cisão entre as lutas por direitos das mulheres balconistas versus os direitos das trabalhadoras domésticas - em sua maioria, mulheres negras no Sul dos Estados Unidos. ${ }^{30}$ Dessa forma, o corte significativo de uma diferença no trabalho apresenta-se, nesse caso específico, não nas diferenças em termos de classe ou gênero, mas sim de raça. $O$ acesso ao emprego, no capitalismo, segundo a leitura proposta por Davis, é eminentemente racializado - especialmente se pensarmos em países que até a metade do século XIX eram escravagistas, como Estados Unidos, Brasil, Cuba etc. Isso, claro, não ignora também as formas pelas quais o acesso ao emprego tende a passar por uma divisão sexual do trabalho, que contempla também formas específicas de divisão em termos de gênero e sexualidade no acesso ao trabalho.

Dessa forma, o que a autora desdobra em Mulheres, raça e classe é a necessidade de reconhecer "formas específicas de opressão", ${ }^{31}$ que por sua vez foram historicamente secundarizadas conforme as lideranças de diversas lutas focaram exclusivamente em uma identidade ou percepção social para angariar a luta. Desde o século XIX, Davis mostra que havia pontos de conexão às múltiplas formas de opressão

$30 \quad$ No artigo "E se o trabalho não fosse branco e masculino? Recentrando a história da classe trabalhadora e estabelecendo novas bases para o debate sobre sindicatos e raça", David E. Roediger sintetizou um argumento caro a W.E.B. Du Bois em Black Reconstruction, ou seja, a ideia de um "salário psicológico" (psychological wage), onde o trabalhador branco detinha mais amplo acesso a direitos e privilégios, não obstante seu salário fosse pequeno. Essa vantagem psicológica garantia maior deferência pública e, por sua vez, seria crucial para pensar os estudos sobre a questão racial nas organizações da classe trabalhadora. Ver: ROEDIGER, David. E se o trabalho não fosse branco e masculino? Recentrando a história da classe trabalhadora e estabelecendo novas bases para o debate sobre sindicatos e raça. In: FORTES, Alexandre et. al. Cruzando fronteiras: novos olhares sobre a história do trabalho. São Paulo: Ed. Fundação Perseu Abramo, 2013. p. 50-51. Ver também DU BOIS, W.E.B., op. cit., p. 785-786. DAVIS, op. cit., 2016, p. 159. 
em todas as principais lutas sociais, mas que essas tinham de enfrentar pensamentos classistas e patriarcais que buscavam anular qualquer ideia de heterogeneidade dos sujeitos, em especial da mulher, negra, da classe trabalhadora.

Não obstante a reflexão histórica proposta por Angela Davis, contudo, a ideia de "formas específicas de opressão" nos diz pouco sobre como elas operam efetivamente. Em outras palavras, há uma ausência no texto que diz respeito a uma "teoria da opressão", que consiga efetivamente relacioná-la à ideia de "exploração". Nesse ponto, Abigail Bakan em um intrigante ensaio chamado "Marxismo e Antirracismo" aponta uma possibilidade de relação entre opressão e exploração por meio não de uma historicidade específica, mas sim por meio de um conceito tripartite que interliga exploração, opressão e alienação. Para Bakan, esses conceitos revelam diferentes "processos de conflito social disciplinados por uma ordem", ainda que, como a autora afirma, "cada processo opera com sua própria dinâmica". ${ }^{32}$ Todavia, em termos analíticos, eles também são conceitos interativos, pois procuram dar conta de processos de conflito social que ocorrem dentro de outros conflitos sociais.

Isso fica evidente na apreciação que Bakan faz de muitos marxistas que analisam o racismo, como Robin Blackburn, W.E.B. Du Bois, C.L.R. James, August Nimtz, Walter Rodney, Eric Williams e, claro, Angela Davis. A partir dessa apreciação, a autora procura demonstrar justamente como o racismo não pode ser reduzido somente ao conceito de exploração. Não obstante as consequências econômicas do racismo serem vitais para a própria forma de acumulação do capitalismo, a discriminação racial se desdobra em outros processos de conflito social. Ao mesmo tempo, essa discriminação, quando opera em termos de alienação e opressão, ela passa a ser invisibilizada e reificada. E mesmo que sejam centrais para a reprodução do capitalismo, cada um desses termos opera de forma distinta.

A noção de alienação, retomada por Bakan, discute não apenas o grau de alienação em relação ao trabalho, numa leitura marxiana, mas também a converte em termos psicanalíticos para aquilo que Fanon chamou de "alienação psíquica do negro". E, nesse sentido, a sua obra trava profundo diálogo com essas questões, destacando como a alienação opera num duplo diante das estratégias de racialização ocidental: por um lado, ela aliena os sujeitos do produto do seu trabalho; por outro, aliena o sujeito negro (ou não branco) de um sujeito branco universal. Nos dizeres do próprio Franz Fanon, a consciência negra aparece sempre como imanente a si própria e também aderente a si própria, refratária a um sujeito universal. ${ }^{33}$

32 BAKAN, Abigail. Marxismo e antirracismo: repensando a política da diferença. Revista Outubro, $\mathrm{n}$. 27, p. 48, nov. 2006.

33 O argumento de Fanon complexifica a narrativa de Sartre em Orfeu Negro. Nesse ensaio, o filósofo francês argumentara que a diferença entre a noção de classe e a noção de raça era que a primeira 
Essa dualidade da alienação carrega consigo uma contradição, por sua vez. Por um lado, o sujeito trabalhador se universaliza ao ser alienado do seu trabalho, mas por outro a sua alienação se particulariza ao ser racializada. Mas essa forma particular não ignora a primeira; pior, pois uma condiciona a outra, o que nos joga para uma outra dialética onde, por um lado, o "racismo enevoa as distinções de classe" 34 e, por outro, as distinções de classe podem enevoar o racismo. Dito de outra forma, a alienação que separa o trabalhador dos demais trabalhadores pode torná-los insensíveis aos processos de racialização sofridos e, por outro lado, os processos de racialização podem separá-los enquanto trabalhadores.

Isso nos leva a discutir os termos do conceito de opressão, que Bakan define justamente pelo vazio teórico na teoria marxista. O conceito, por si só, nunca foi operacionalizado por Marx diretamente e o uso que muitos marxistas fazem remete a relações de dominação que não são precisamente especificadas, dependendo por vezes de algum aditivo (opressão de gênero, ou opressão de classe, ou opressão de raça, entre outras). Todavia, Bakan consegue pensar a partir de uma outra lógica dual de opressão presente no próprio Marx. Essa dupla natureza se encontraria tanto na exploração tradicional do capitalismo sobre a força de trabalho, mas também se encontra na desenfreada competição entre trabalhadores. ${ }^{35}$ Isso permite um olhar sobre opressão entendida, na lógica capitalista, como um motor crucial para que patrões e capitalistas estimulem a competição entre trabalhadores - e, dessa forma, as opressões de gênero, de raça (e mesmo outras) são vitais para o processo de acumulação de capital.

Em última instância, Bakan chama atenção para a articulação entre essas diferentes relações de dominação que são originárias do conflito social e, dialeticamente, moldam esses e novos conflitos ao longo do tempo. A exploração capitalista é determinante do modo de produção, mas a alienação do trabalho e do próprio corpo de diversos trabalhadores decorre de sistemas de opressão que, por sua vez, estimulam a competição entre trabalhadores e trabalhadoras, minando redes de solidariedade. E quanto maiores as opressões a que são sujeitos, quanto mais profunda a alienação que sofrem, tendencialmente será ainda mais profunda a exploração sofrida. É nesses cruzamentos entre alienação, exploração e opressão,

seria universal e abstrata, enquanto a segunda seria concreta e particular. Assim, a única chance de um projeto emancipatório universal ser forjado politicamente seria por meio da noção de classe. Por sua vez, a resposta de Fanon é certeira: ao legar a noção de raça apenas o lugar do particularismo, isso significava que a experiência de homens e mulheres negras seria intangível a uma concepção universal. Ver FANON, Franz. Pele negra, máscaras brancas. Salvador: EDUFBA, 2008. p. 120 122.

34 BAKAN, op. cit., p. 57.

35 Ibidem, p. 65. 
por sua vez, que os sujeitos constituem suas identidades, ou seja, por meio de conflitos sociais que derivam das relações de dominação nas quais eles nascem e as que lhes são impostas.

Todavia, retomando o argumento de Davis, a obra Mulheres, raça e classe não procura qualificar essas categorias de exploração, opressão e alienação em termos teóricos, mas sim por meio das experiências de homens e mulheres, consolidando uma narrativa empírica onde esses diferentes processos de conflito social operam, por vezes, de forma desigual e combinada. Um exemplo interessante do tipo de combinação oriunda dos diferentes conflitos pode ser visto a partir do discurso de Sojourner Truth, "Não sou eu uma mulher?" (Ain't I a woman?). Nesse célebre discurso das lutas sociais nos Estados Unidos, proferido em 1851, Davis destaca os múltiplos conflitos evidentes na fala de Truth, ex-escrava, mulher, negra, trabalhadora. A experiência aparece, por assim dizer, como um cruzamento doloroso de opressões, de alienação e exploração, ganhando assim uma multiplicidade vertiginosa:

Arei a terra, plantei, enchi os celeiros, e nenhum homem podia se igualar a mim! Não sou eu uma mulher? Eu podia trabalhar tanto e comer tanto quanto um homem - quando eu conseguia comida - e aguentava o chicote da mesma forma! Não sou eu uma mulher? Dei à luz treze crianças e vi a maioria ser vendida como escrava e, quando chorei em meu sofrimento de mãe, ninguém, exceto Jesus, me ouviu! Não sou eu uma mulher? ${ }^{36}$

Creio que é possível auferir, a partir de Truth - e da leitura proposta por Davis, que seu discurso expôs o "viés de classe e o racismo" do movimento feminista americano na metade do século XIX. ${ }^{37}$ Mas mais do que isso, na análise que Angela Davis propôs sobre o célebre discurso, fica evidente que termos como opressão, exploração e alienação emergem nas experiências do sujeito, interagindo um com o outro; maternidade, trabalho, cor da pele, violência, estava tudo ali, tudo constituía sua experiência. Faltaria ainda um estudo específico sobre as formas de agência capaz de dilatarem os limites traçados, mas conforme a história social se debruça sobre diferentes relações sociais, começamos a ter uma visão mais abrangente sobre como os sujeitos conseguem resistir a determinadas formas de conflito social onde eles são explorados, oprimidos ou alienados.

Creio que o que Bakan deixa em aberto aqui é a possibilidade de uma noção mais ampla de exploração, opressão e alienação. Trata-se de relações sociais que, por sua vez, engendram formas especificas de conflito, mas são também relações complementares. A eventual primazia de qualquer uma delas refere-se muito mais a

DAVIS, op. cit., 2016, p. 71.

Ibidem, p. 73. 
um recorte analítico específico, no que a proposta da autora é justamente evidenciar as conexões entre elas. Em última instância, ao perceber tais interconexões, creio ser possível afirmar que os historiadores serão capazes de análises cada vez mais complexas e, mais do que isso, terão a possibilidade de administrar autores de diferentes tradições, como Davis e Thompson, reconhecendo que a heterogeneidade da classe trabalhadora se dá pela sua conexão com gênero e raça, onde um elemento sempre se torna capaz de informar as formas de dominação e resistência que operam um no outro. ${ }^{38}$

\section{Uma tentativa de conclusão e uma homenagem: interseccionalidades em diálogo}

Invariavelmente, esse texto não discutiu abertamente a noção de "intersecção", tendo em vista que Davis, ainda que entusiasta da leitura de Kimberlé Crenshaw, não se propõe a discutir especificamente o conceito em Mulheres, raça e classe. ${ }^{39}$ Mas conforme o termo tem sido apropriado nas lutas sociais contemporâneas, me parece importante resgatá-lo a título de conclusão. A obra de Davis, ao entrar no mercado brasileiro de forma tardia, abre uma série de possibilidades para que os historiadores possam refletir como, de fato, as interações entre classe, raça e gênero acabam configurando determinadas experiências por meio da própria influência contemporânea dessas discussões dentro das esquerdas e dos movimentos sociais. Tais experiências dizem respeito às relações sociais construídas historicamente no capitalismo e, por sua vez, permitem que os historiadores questionem como esses conflitos sociais, inerentes a essas relações, se transformaram ao longo do tempo - para utilizar aqui os termos de Bakan. É difícil saber ao certo o quanto essas linhas de diálogo entre autores de tradições tão diferentes podem, de fato, constituir ferramentas para a construção de uma historiografia cada vez mais sensível aos cruzamentos de conceitos, conflitos e relações sociais. Esse artigo e seu autor estão cientes desse impasse.

38 David Roediger, na introdução de seu livro Class, Race and Marxism, aponta que um dos impasses das leituras mais contemporâneas sobre marxismo - mais especificamente, referentes ao geógrafo David Harvey - é a ausência de discussão sobre como a questão racial é vital para a sobrevivência e manutenção do sistema. Sem discutir em termos específicos de exploração, opressão, ou alienação, Roediger questiona o argumento de marxistas que compreendem que a lógica do capital não depende necessariamente de raça (e mesmo de gênero) para ser operacionalizada. Ver: ROEDIGER, David. Class, Race and Marxism. Nova York: Verso, 2017. p. 3 e 19. Para o historiador americano, contudo, raça, assim como gênero, evidenciam elementos intrínsecos ao capital que não podem ser ignorados pelos historiadores. É precisamente nessa articulação entre diferentes relações sociais que é possível ver ainda a força do capital - e que, portanto, é para onde se apontam as possibilidades de resistir a ele.

39 Há uma série de palestras e seminários de Angela Davis nos quais ela toca nessa questão, mas convém destacar que Mulheres, raça e classe, publicado em 1983, precede o artigo seminal de Crenshaw de 1989. 
Todavia, ler Thompson por meio de Davis, ou ler Davis por meio de Thompson, é uma tentativa de estabelecer novos marcos para pensarmos uma teoria crítica da História Social, capaz de questionar silêncios historiográficos que Thompson não conseguiu dar conta em sua obra e, por sua vez, criar uma gramática a qual os historiadores e historiadoras possam operacionalizar as diferentes relações de dominação discutidas na obra de Davis. A título de pós-escrito, contudo, refletindo sobre o caráter de homenagem a Beatriz Loner neste dossiê, considero que uma tentativa de aproximação entre Thompson e Davis seria um esforço que a "Bia" criticaria bastante: apontaria os limites, seria rígida nos critérios avaliativos, mas que eu espero que ela pudesse reconhecer, nesse tipo de iniciativa, o seu próprio esforço enquanto historiadora e pesquisadora que deixou um imenso legado à História Social do Trabalho.

É natural que dessa leitura que aqui propus surjam outras análises e que comecem a emergir problematizações sobre os rumos aqui propostos. Todavia, um dos pontos centrais na análise feita por Angela Davis é a ideia de que a "diferença" constitui uma "fagulha criativa", na qual as tradições das esquerdas, partidos e movimentos sociais tendem a tornar-se mais amplos e democráticos quando confrontam seus próprios limites - e creio que o mesmo pode ser dito dos intelectuais. ${ }^{40}$ Se as "diferenças" que emergirem deste texto contribuírem para ampliarmos os significados da emancipação social, creio que isso por si só já constitui um grande avanço para a História Social do Trabalho. E gostaria de pensar que Beatriz Loner, a "Bia", seria uma das mais principais vozes a formular essa fagulha criativa, como ela sempre foi.

Recebido em 22/08/2019

Aprovado em 25/10/2019

40 DAVIS, op. cit., 2011. 